Review Article

\title{
Overview of Epidemiology of Malaria Associated with Pregnancy in Northwestern Colombia, | 985-2020
}

\author{
Jaime Carmona-Fonseca', Jaiberth Antonio Cardona-Arias ${ }^{2}$
}

${ }^{1}$ Professor, School of Medicine, University of Antioquia. Coordinator "Grupo Salud y Comunidad-César Uribe Piedrahita", Universidad de Antioquia. Medellín, Colombia.

${ }^{2}$ Professor, School of Microbiology, Universidad de Antioquia. Medellín, Colombia.

DOI: https://doi.org/10.24321/0019.5138.202184

I $\quad \begin{array}{lllll}\mathbf{N} & \mathbf{F} & \mathbf{O}\end{array}$

\section{Corresponding Author:}

Jaiberth Antonio Cardona-Arias, School of Microbiology, Universidad de Antioquia.

Medellín, Colombia.

E-mail Id:

jaiberth.cardona@udea.edu.co

Orcid Id:

https://orcid.org/0000-0002-7101-929X

How to cite this article:

Carmona-Fonseca J, Cardona-Arias JA. Overview of Epidemiology of Malaria Associated with Pregnancy in Northwestern Colombia, 19852020. J Commun Dis. 2021;53(4):140-147.

Date of Submission: 2021-09-13

Date of Acceptance: 2021-12-23
$\begin{array}{llllllll}\mathbf{A} & \mathbf{B} & \mathbf{S} & \mathbf{T} & \mathbf{R} & \mathbf{A} & \mathbf{C} & \mathbf{T}\end{array}$

Background: Knowledge about malaria associated with pregnancy (MAP) is scarce in Latin America and Colombia.

Methodology: This paper presents an overview of studies captained in Pubmed, Lilacs, GoogleScholar and thesis repositories from six Colombian universities and bibliographic references of manuscripts.

Results: The following topics have been described: study sites, infectious agents, genetic variation of Plasmodium in MAP, vector resistance to insecticides, incubation period, natural susceptibility and resistance to infection, immunity in MAP, frequency, coexistence of gestational (GM) and placental (PM) malaria, associated factors, efficacy of antimalarial treatment, material living conditions in MAP. The MAP has a high prevalence, with a high frequency of submicroscopic infections. There are cases of MAP due to $P$. falciparum, $P$. vivax, or both. Monotherapy with chloroquine or amodiaquine for MAP for $P$. vivax has efficacy greater than $95 \%$ and artemether-lumefantrine or artesunate-mefloquine $100 \%$ for $P$. falciparum. There are high rates of anemia in pregnancies (30-70\%). In "The Region," there is no problem of resistance of vectors to insecticides. MAP occurs in poor territories, with interaction of food insecurity, chronic malnutrition, dissatisfaction of basic needs, intestinal parasites, violence and abuse of human rights.

Conclusions: MAP study is just beginning in Colombia; there are no programmes that effectively operate to detect and solve this problem; Government agencies, international health organizations, and private companies should finance the multidisciplinary and comprehensive research (natural and social) of the MAP, in order to know its main characteristics throughout the country and use that knowledge as a basis to seek solutions.

Keywords: Malaria, Plasmodium, Pregnancy, Placenta, Neonate, Epidemiology, Colombia 


\section{Introduction}

Knowledge about malaria associated with pregnancy (MAP) is scarce in Latin America and Colombia. MAP has three presentations: gestational malaria (GM), placental malaria (PM), and congenital malaria (CM); Colombian health agencies do not disclose data on them. MAP occurs owing to infection by one of the five species that affect humans: $P$. vivax, $P$. falciparum, P. malariae,,$^{1,2} P$. ovale ${ }^{2}$ and $P$. knowlesi $;^{3}$ of $P$. cynomolgi, simian plasmodia, a case of natural human infection is known, a Malaysian woman without pregnancy. ${ }^{4}$

The information on MAP in Africa shows that the problem is serious according to its frequency, effects on maternal and child health, and economic consequences. ${ }^{5-7}$ In Colombia MAP is also a serious clinical and public health problem, but with lower frequency. ${ }^{8-11}$ The great area of the north of the country, from the Urabá Antioqueño region, to the west, the upper basins of the Sinú and San Jorge rivers, in the south of the department of Córdoba, and finally, to the east, the Bajo Cauca Antioqueño and the south of the department of Bolívar (hereinafter, the area is called "La Region") (Figure 1 ), generates more than $60 \%$ of the registered cases $^{12}$ and is the one that concentrates the scientific production on MAP in Colombia. "La Region", as all of Colombia, it does not have significant problems with the resistance of vectors to insecticides or of the parasites to antimalarials; these do not explain the high and sustained morbidity; instead, the social, economic, political and cultural determinants of the disease are more relevant to explain the permanence of the disease in the territory. ${ }^{13}$

The reports on MAP in Colombia are few and scattered over time; For this reason, it is necessary to compile them to improve understanding of the problem and the current state of the country in this field of research.

\section{Methodology}

A systematic search of original studies on MAP was carried out in the 25 municipalities of "La Región."12 Information was searched in Pubmed, Lilacs, and Google Scholar; This search strategy was used (malaria AND [pregnancy OR pregnancy] AND Colombia). In addition, thesis repositories from the Colombian universities of Antioquia, Córdoba, Valle, Cartagena, Norte-Barranquilla and Nacional, the documentary archive of the research group of the authors of this manuscript, and the references of articles and thesis were consulted. The studies were published between 1985 and 2020, all the studies captured were included regardless of their quality.

\section{Results and Discussion}

The topics that have been investigated in MAP in Colombia since 1985 include preclinical studies on characteristics of the vector, Plasmodium, immunity and resistance to infection; as well as designs from classical epidemiology (mainly observational) and study on socioeconomic conditions (Figure 2).

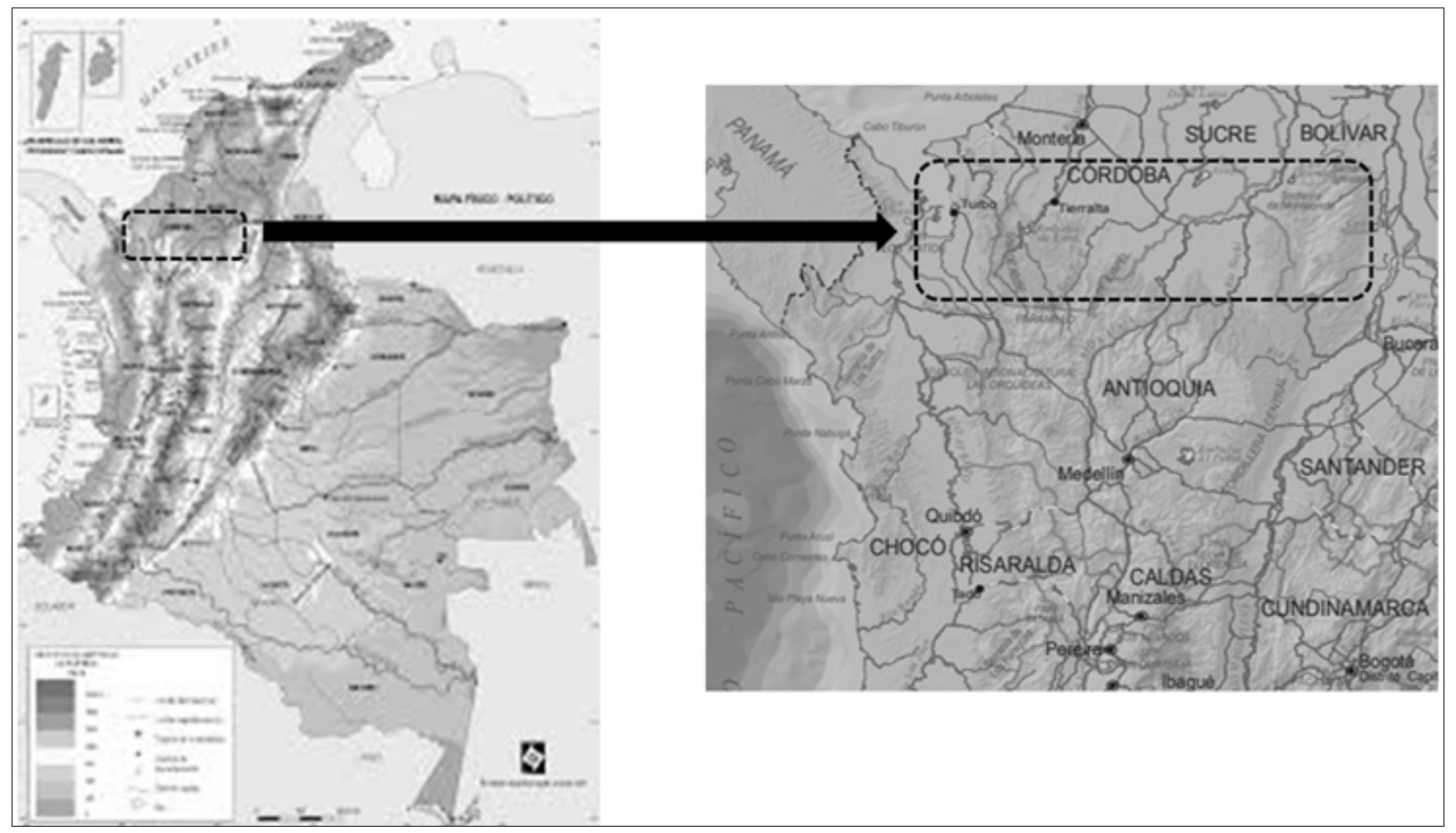

Figure I.The Great Malarious Zone in Northwestern Colombia (“La Región”)

Note: Three deparments: Antioquia with Urabá and Bajo Cauca; Córdoba with Valencia, Tierralta, Puerto Libertador and Montelíbano; and Bolívar with Montecristo, Santa Rosa del Sur, Norosí y Tiquisio (Puerto Rico) 


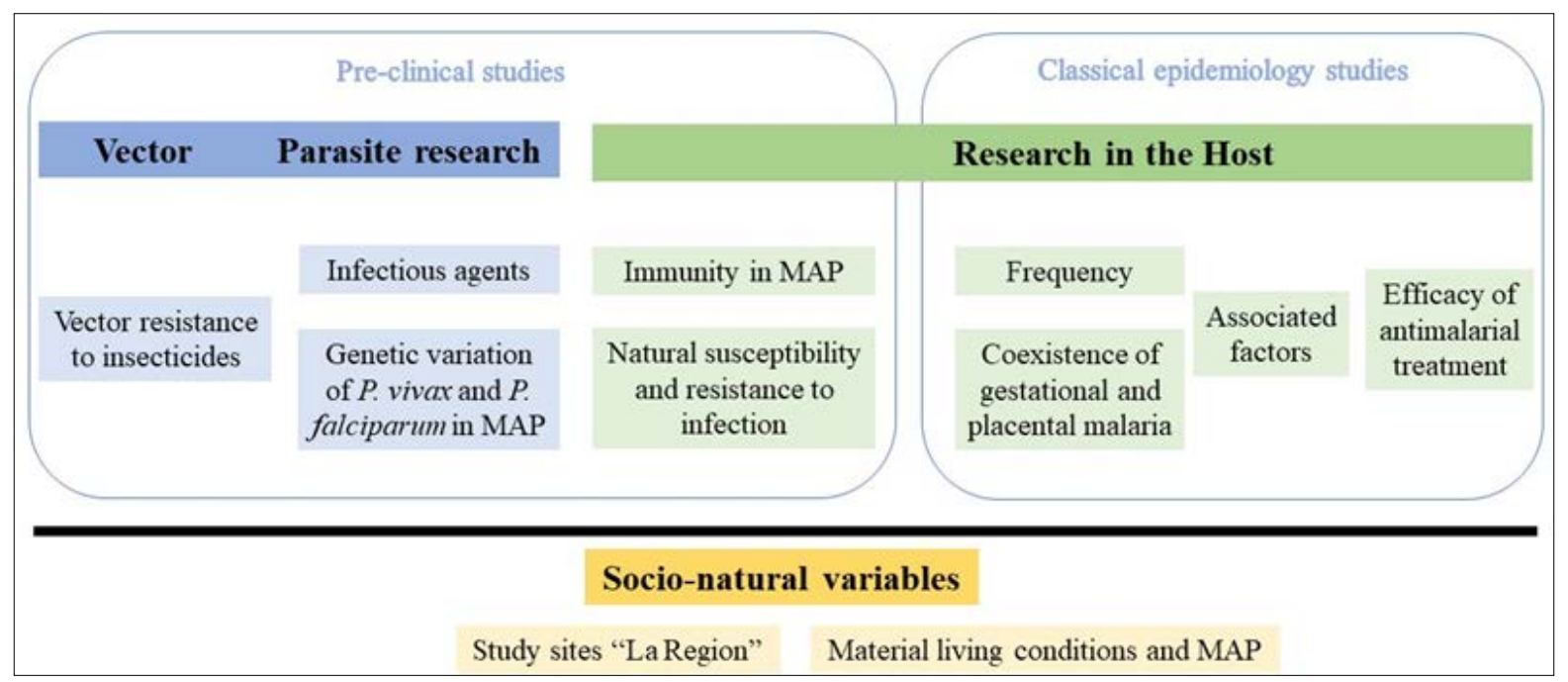

Figure 2.Scheme of the Topics Investigated on MAE Colombia I 985-2020.

\section{“La Region”}

"La region," in which the studies were carried out, has been specifically described, it has $\approx 35,000 \mathrm{~km}^{2}$ area and 1.1 million inhabitants, all exposed to malaria; has an annual parasite index> 25/ 1,000 exposed, stable transmission (it does not have marked fluctuations in annual cases of malaria), and Plasmodium vivax predominates (60-70\% of the total). ${ }^{12}$

\section{Material regarding Living Conditions and MAP}

It is evident that Colombian research on MAP is too scarce, and that reference to its "social variables" is almost nil. In the specific case of pregnant women, women in labor and their children, some studies have also been carried out ${ }^{14,15}$ that are consistent with what was found in the general population ${ }^{16}$ and allow us to affirm that this situation of poverty is typical of the entire "La Region."

It has been known with enough arguments and for too many decades that malaria is a disease of social groups with the worst socioeconomic conditions; it is not a "disease of the tropics" but a disease of the most exploited and marginalized people who reside in the tropics. In this area of the country, the common denominator of living conditions is poverty (higher than the average for the department and the country) derived from its interaction with food insecurity, chronic malnutrition, malaria, intestinal parasites, dissatisfaction of basic needs, violence, and abuse of human rights. ${ }^{13,17,18}$ In these areas, "progress" seems to have been lost, while the social inequality and injustice that affect malarias' families is demonstrated, as a result of inequitable economic, political, and social processes in the country. ${ }^{17}$

\section{Vector Resistance to Insecticides and Infectious agents of MAP}

In "La Region," there is no problem of resistance to insecticides by Anopheles. ${ }^{19-21}$ In the region, MAP is caused by $P$. falciparum, $P$. vivax or both (mixed infection), ${ }^{10,22-29}$ cases of $P$. malariae are unknown, which is endemic in small foci of Valle Del Cauca and Amazonia. ${ }^{30,31}$

We did not find information on incubation periods in "La Region," this must be the same as for malaria in the general population: $P$. falciparum 12 days (7-14 days), $P$. vivax and $P$. ovale 14 days (8-14 days), $P$. malariae 7-30 days. It is not defined for $P$. knowlesi (morphologically indistinguishable from $P$. malariae) even in the most recent reviews. ${ }^{32,33}$

\section{Genetic Variation of $P$. vivax and P. falciparum in MAP}

In pregnant women from "La Region," the genetic variation of $P$. falciparum and $P$. vivax was studied from plasmodial isolates from four sources: non-pregnant, placenta, maternal peripheral blood at delivery and during prenatal consultation, using the index fixation Fst (estimated by single nucleic polymorphisms or microsatellites), which takes values between zero (complete panmixis, the two populations are mixing freely) and one (all genetic variation is explained by the population structure); a higher Fst indicates greater genetic differentiation of parasites. In Colombian $P$. vivax infections, no genetic differentiation was found between the plasmodia of the four groups, but in P. falciparum infections the Fst index showed significant differences from the parasites obtained at the time of delivery (peripheral blood and placenta), with parasites obtained from pregnant women in prenatal control and in non-pregnant women (the latter two did not show differences). ${ }^{19,26,27}$

Another study with a pregnant and non-pregnant population infected with $P$. vivax, found that pregnant women presented a greater number of different alleles, both in primary infection (PI) (34 alleles) and in recurrence (RR) (23 alleles), compared with non-pregnant (26 different alleles in $\mathrm{PI}$ and 
8 in RR). Pregnant and non-pregnant women had infections with several clones in PI and RR, the microsatellite Pv3, 27 was detected in most polyclonal infections. The frequency of RR in pregnant women was $46 \%$ and in non-pregnant women $13 \%$. RRs in pregnant women were genetically heterologous in $68 \%$ and homologous in $21 \%$, while in non-pregnant women they were heterologous in $67 \%$ and homologous in 33\%. The pregnant women had higher levels of Fox-P3 expression in the PI compared to the RR ( $p<0.05)$, while the non-pregnant women did not have significant differences between the PI and RR moments in any of the immune mediators analyzed. There were no significant differences between the times of admission and recurrence for any of the immune mediators analyzed (TNF, IFN- $\gamma$, IL-8, IL-13, TGF- $\beta$, IL-10, PD-L1, Fox-P3) in patients with parasites genetically homologous or heterologous to the initial infection. ${ }^{34}$

In 46 patients with uncomplicated malaria (33\% pregnant and $67 \%$ men) caused by $P$. falciparum, residents of Tierralta, Córdoba, a low genetic variation of the plasmodial species that circulate in Colombia was demonstrated; For this reason, it is plausible to think that a vaccine developed with conserved antigens generates a high effectiveness against MAP in this country. This same study suggests that the plasmodia circulating in the country come from Africa, and are genetically different from those reported in other South American countries. ${ }^{35}$

\section{Immunity in MAP}

A multicenter study with 572 pregnant women from 5 endemic countries for malaria (including Colombia), some with $P$. vivax infection and others without infection, indicates that in GM vivax the predominant immune response is Th1 and pro-inflammatory, when it is balanced with antiinflammatory cytokines can prevent negative outcomes during labor, while exacerbating the Th2 response may present deleterious effects during delivery. ${ }^{36}$

Gnidehou's study in Colombia reported the presence of anti-VAR2CSA antibodies in pregnant women, men and children exposed to malaria, which inhibit the adhesion of infected erythrocytes to chondroitin sulfate A (CSA) in vitro. ${ }^{37}$ However, a later study indicated that said IgG antibodies against VAR2CSA were not specific for plasmodial infection, highlighting that the specific antibodies are limited to the gestational period. ${ }^{38}$

A study in 2019 with non-pregnant women exposed to $P$. vivax showed that antibodies anti-Duffy binding protein, have cross-reactions with VAR2CSA and prevented adhesion of the parasite to CSA. ${ }^{39}$ Furthermore, Gnidehou \& Yanow, in 2020, determined multiple variables that can affect the detection of IgG antibodies against VAR2CSA: differences in the native and recombinant protein, type of antigens, phase of infection, analytical method and the low study of the functionality of IgG antibodies since in many cases only the reactivity is determined. ${ }^{40}$

Other authors have studied variations in the classical immune response against the parasite, specifically the way in which Plasmodium displays polymorphic epitopes to evade the immune response. In pregnant women, this implies the possibility of designing vaccines to cryptic epitopes, and in this way, achieving the production of antibodies that protect against multiple Plasmodium strains. $^{41}$

Most of the studies on the immune response in MAP focus mainly on $P$. falciparum infections, they agree that the consequences of MAP go beyond infection during pregnancy, since its effects extend to the neonate and the first years of life. ${ }^{25}$

In pregnancy is not known how antiplasmodial antibodies (Ab) maintain protective levels, and its levels in reinfections are not known either. Despite this absence, a study in northwestern Thailand measured Ab levels against merozoite antigens $(\mathrm{m}-\mathrm{Ag})$ from both species and against VAR2CSA antigens from $P$. falciparum. The Ab against Ag-m of the two species are not constant, with high heterogeneity due to variations in the exposure; furthermore, a potentiation of this response was recorded in each new infection, with a duration of the immune response against $\mathrm{m}-\mathrm{Ag}$ for about 1-8 years. ${ }^{42}$ This indirect evidence of immune memory has also been attempted to support cross-reactivity between species $P$. vivax and $P$. falciparum. ${ }^{43}$

\section{Natural Susceptibility and Resistance to Infection}

Human susceptibility for each species is general, except that of blacks with respect to $P$. vivax, who have resistance since, in general, they lack the Duffy antigen (DARC or Fy glycoprotein (FY) or CD234), which is a mandatory receptor used by that plasmodium to invade erythrocytes. ${ }^{44}$ The few studies, that have addressed this issue, conclude that the susceptibility of pregnant women is greater than that of those without pregnancy. ${ }^{45,46}$

\section{Frequency MAP}

The frequency of GM with TBS can range between $1.0 \%$ and $23.0 \%{ }^{9,36,41}$ and, with PCR, it rises to $49 \% .{ }^{24,28,47} \mathrm{MP}$ with TBS has been reported in a range of $2 \%$ to $12 \%$, which with PCR rises to $57 \% .^{22,28,48}$ The $\mathrm{CM}$ ranges between $0.2 \%$ and $2.0 \%$ and with PCR it reaches $29 \% .^{22,28,29,48}$

With TBS, the prevalence of GM was somewhat higher than the incidence (10.39\% vs $9.28 \%$ ) in a previous study. ${ }^{48}$ Something similar occurs with the prevalence in another investigation: ${ }^{23} 14.0 \%$ with TBS and $9.1 \%$ with nested PCR. The situation becomes more difficult when knowing that $79 \%$ of the infections diagnosed with qPCR were 
submicroscopic; ${ }^{23}$ these are asymptomatic but effective in maintaining transmission. ${ }^{26,47}$ The comparison of the diagnostic tests (TBS vs set of PCR varieties) shows that the frequency can be quadrupled when applying PCR. Something similar occurs with the prevalence of PM and $\mathrm{CM}$, demonstrating that submicroscopic infections (detected with PCR, but not with TBS) affect maternal health, the placenta and affect the gestational product. ${ }^{23,25,26}$

\section{Coexistence of GM and PM}

$\mathrm{GM}$ is prior to infection of the placenta (PM). The first can exist without the second and PM can be without GM, but the usual is their coexistence. The study in four municipalities of Urabá Antioqueño in 293 parturient women and their placentas found a highly significant coexistence between GM and PM according to the $\mathrm{TBS}^{48}$ among 27 positive results in the mother, $63 \%$ were positive in the placenta; among 19 positive results in the placenta, $89 \%$ were positive in the mother. Another reading of these data is this: when the TBS is positive in the mother, the probability that it is positive in the placenta is $63 \%$, compared to $89 \%$ that it is positive in the mother when it is positive in the placenta.

\section{Associated Factors}

In a Colombian study with 2,117 pregnant women, the average age was $23.1 \pm 5.2$ years; those under 18 years of age represented $18 \%$, those of $18-24$ years $47 \%$, those of 25-39 years contributed $33.5 \%$ and those of $40-46$ years contributed with $2 \%$ of the total cases of GM. ${ }^{48}$ It has also been documented that, in MAP, the length of residence in the malarious area (as a proxy for the number of malaria attacks suffered in life) and the number of malaria attacks suffered during pregnancy are more important than age. In general, the number of GM attacks is associated with age, with the time of residence in the malarious area, with parity (number of pregnancies and deliveries), but all this is an approximation of the only important thing: number of episodes suffered of MAP; since the immune experience obtained and accumulated outside of pregnancy does not protect against MAP. ${ }^{49}$

\section{Efficacy of Antimalarial Treatment}

This review found two papers on the treatment of GM, one investigation evaluated the response of pregnant women with uncomplicated falciparum malaria to treatment with artemether-lumefantrine or artesunate-mefloquine and the response was adequate in $100 \%$. Both studies measured the response of pregnant women with uncomplicated vivax malaria to chloroquine monotherapy and the response was adequate in $95-100 \%$ and one of these reports indicates an adequate response to amodiaquine monotherapy in $97-100 \% .^{50,51}$

Standard treatment with chloroquine (CQ) or amodiaquine (AQ) as schizonticides against $P$. vivax also succeeds in eliminating the gametocytes of this plasmodium. In contrast, schizontocidal treatment against $P$. falciparum does not eliminate them, whether or not it has artemisinin derivatives; for this reason, primaquine should be added to the schizontocide, which should not be used in case of pregnant women. ${ }^{52}$

\section{Conclusion}

The study of MAP is just beginning in Colombia; its frequency with PCR is high, with a high frequency of submicroscopic infections. There are no programmes that effectively work to detect and solve these problems. Government agencies, international health organizations, and private companies should finance the multidisciplinary and comprehensive research (natural and social) of the MAP, in order to know its main characteristics throughout the country and use that knowledge as a basis to seek solutions.

\section{Declarations}

\section{Data Availability}

The data used to support the findings of this study are available from the corresponding author upon request.

\section{Authors' Contributions}

JCF designed the study, obtained funding, performed the analyzes, wrote the manuscript, and reviewed the final version. JACA performed the analyzes, wrote the manuscript, and reviewed the final version.

\section{Funding Statement}

- Colciencias/Minciencias. Project code 111577757051 , contract 755-2017

- Universidad de Antioquia

\section{Conflicts of Interest: None}

\section{References}

1. Bergström S, Fernandes A, Schwalbach J, Perez O, Miyar R. Materno-fetal transmission of pregnancy malaria: an immunoparasitological study on 202 parturients in Maputo. Gynecol Obstet Inves. 1993;35:103-7. [PubMed] [Google Scholar]

2. Williams J, Njie F, Cairns M, Bojang K, Coulibaly SO, Kayentao K. Non-falciparum malaria infections in pregnant women in West Africa. Malar J. 2016 Jan;15:53. [PubMed] [Google Scholar]

3. Barber BE, Bird E, Wilkes CS, William T, Grigg MJ, Paramaswaran U, Menon J, Jelip J, Yeo TW, Anstey NM. Plasmodium knowlesi malaria during pregnancy. J Infect Dis. 2015 Apr;211:1104-10. [PubMed] [Google Scholar]

4. Ta TH, Hisam S, Lanza M, Jiram Al, Ismail N, Rubio JM. First case of a naturally acquired human infection with Plasmodium cynomolgi. Malar J. 2014 Feb;13:68. [PubMed] [Google Scholar] 
5. Rogerson SJ, Meghna D, Mayor A, Sicuri E, Taylor SM, van Eijk AM. Burden, pathology, and costs of malaria in pregnancy: new developments for an old problema. Lancet Infect Dis. 2018 Apr;18:e107-e18. [PubMed] [Google Scholar]

6. Bauserman M, Conroy A, North K, Patterson J, Bose C, Meshnick S. An overview of malaria in pregnancy. Semin Perinatol. 2019 Aug;43:282-290. [PubMed] [Google Scholar]

7. Restrepo-Posada DC, Carmona-Fonseca J, CardonaArias JA. Systematic review of microeconomic análisis of pregnancy-associated malaria. Heliyon. 2020 Jul;6:e04558. [PubMed] [Google Scholar]

8. Restrepo-Posada DC, Carmona-Fonseca J, CardonaArias JA. Cost-effectiveness of rapid diagnostic tests, compared to microscopic tests, for the diagnosis and treatment of gestational malaria in Colombia from an institutional perspective. Malar J. 2020 Nov;19:400. [PubMed] [Google Scholar]

9. Arismendi Solano MJ. Magnitud de la malaria gestacional en el Urabá Antioqueño, período 20002006. Medellín: Universidad de Antioquia;. 2008. 119 p. Spanish. [Google Scholar]

10. Carmona-Fonseca J, Maestre A. Prevention of Plasmodium vivax malaria recurrence: efficacy of the standard total dose of primaquine administered over 3 days. Acta Trop. 2009 Nov;112:188-92. [PubMed] [Google Scholar]

11. Bardají A, Martínez-Espinosa FE, Arévalo-Herrera $M$, Padilla N, Kochar S, Ome-Kaius M, Bôtto-Menezes C, Castellanos ME, Kochar DK, Kochar SK, Betuela I, Mueller I, Rogerson S, Chitnis C, Hans D, Menegon M, Severini C, Del Portillo H, Dobaño C, Mayor A, Ordi J, Piqueras M, Sanz S, Wahlgren M, Slutsker L, Desai M, Menéndez C; PregVax Study Group. Burden and impact of Plasmodium vivax in pregnancy: A multi-centre prospective observational study. PLOS Negl Trop Dis. 2017 Jun;11(6):e0005606. [PubMed] [Google Scholar]

12. Carmona-Fonseca J. La Región “Urabá AntioqueñoCuencas altas de los ríos Sinú y San Jorge-Bajo Cauca Antioqueño": "guarida" del paludismo colombiano. Rev Universidad Industrial de Santander. Salud. 2017;49:577-89. Spanish. [Google Scholar]

13. Carmona-Fonseca J. The epidemiology of malaria in Colombia: a heretical view. Medicina Soc. 2020;13:114. [Google Scholar]

14. Carmona-Fonseca J, Arias MM, Correa A, Lemos M. Malaria gestacional y condiciones de vida. Medicina Social. 2011;6:97-107. Spanish. [Google Scholar]

15. Carrasquilla-García YE. Coinfección PlasmodiumGeohelmintos en gestantes: epidemiología, desenlaces materno-neonatales, histopatología placentaria; Colombia, 2017-2019. Medellín: Universidad de
Antioquia; 2021.130 p. Spanish.

16. Ortega-Montes JE, Valencia-Jiménez NN, RestrepoValencia M. La economía política de la pobreza y la desigualdad social: el caso de Montería. Cuaderno de Vivienda y Urbanismo (Universidad Javeriana, Colombia). 2008;1:96-123. Spanish. [Google Scholar]

17. Correa A, Guzmán V, Carmona-Fonseca J, Blair S, Morales D. Alimentación y malaria: una aproximación biosocial. Invest Educ Enferm. 2002;20:30-47. Spanish. [Google Scholar]

18. Robinson JA. La miseria en Colombia. Revista Desarrollo y Sociedad Primer semestre. 2016;76:9-90. Spanish. [Google Scholar]

19. Arango EM. Características genéticas de Plasmodium vivax y Plasmodium falciparum presentes en casos de malaria gestacional y placentaria de Urabá-Altos Sinú y San Jorge-Bajo Cauca, 2005-2011. Medellín: Universidad de Antioquia; 2013. 170 p. Spanish. [Google Scholar]

20. Instituto Nacional de Salud de Colombia. Informe de vigilancia entomológica de malaria Colombia. Bogotá: Instituto Nacional de Salud. 2018; p. 14. Spanish.

21. Orjuela LI, Morales JA, Ahumada ML, Ríos JF, González JJ, Yañez J, Rosales A, Cabarcas D, Venegas J, Yasnot M, Quiñones M. Insecticide resistance and its intensity in populations of malaria vectors in Colombia. Biomed Res Int. 2018 Aug:9163543. [PubMed] [Google Scholar]

22. Agudelo O, Arango E, Maestre A, Jaime CarmonaFonseca J. Prevalence of gestational, placental and congenital malaria in north-west Colombia. Malar J. 2013 Sep;12:341. [PubMed] [Google Scholar]

23. Agudelo O, Aristizabal B, Yanow S.K, Arango E, CarmonaFonseca J, Maestre A. Submicroscopic infection of placenta by Plasmodium produces Th1/Th2 cytokine imbalance, inflammation and hypoxia in women from north-west Colombia. Malar J. 2014 Mar;13:122. [PubMed] [Google Scholar]

24. Agudelo-García OM, Arango-Flórez EM, CarmonaFonseca J. Submicroscopic and asymptomatic congenital infection by Plasmodium vivax or $P$. falciparum in Colombia: 37 cases with placental histopathology and cytokine profile in maternal and placental blood. J Trop Med. 2017:3680758. [PubMed] [Google Scholar]

25. Álvarez-Larrotta C, Agudelo OM, Duque Y, Gavina K, Yanow SK, Maestre A, Carmona-Fonseca J, Arango E. Submicroscopic Plasmodium infection during pregnancy is associated with reduced antibody levels to tetanus toxoid. Clin Exp Immunol. 2019 Jan;195:96108. [PubMed] [Google Scholar]

26. Arango E, Maestre A, Carmona-Fonseca J. Effect of submicroscopic or polyclonal Plasmodium falciparum infection on mother and gestation product: systematic review. Rev Bras Epidemiol. 2010 Sep;13:373-86. 
[PubMed] [Google Scholar]

27. Arango EM, Samuel R, Agudelo OM, Carmona-Fonseca J, Maestre A, Yanow SK. Genotype comparison of Plasmodium vivax and Plasmodium falciparum clones from pregnant and non-pregnant populations in Northwest Colombia. Malar J. 2012 Nov;11:392. [PubMed] [Google Scholar]

28. Arango EM, Samuel R, Agudelo OM, Carmona-Fonseca J, Maestre A, Yanow SK. Molecular detection of malaria at delivery reveals a high frequency of submicroscopic infections and associated placental damage in pregnant women from Northwest Colombia. Am J Trop Med Hyg. 2013 Jul;89:178-83. [PubMed] [Google Scholar]

29. Campos IM. Evaluación de la capacidad diagnóstica de la reacción en cadena de la polimerasa (PCR), la microscopía y la histopatología para la detección de la infección por Plasmodium spp en placenta, sangre periférica materna y sangre del cordón umbilical; Urabá, 2005-2007. Medellín: Universidad de Antioquia. 2009. 180 p. Spanish.

30. Camargo-Ayala PA, Cubides JR, Niño $\mathrm{CH}$, Camargo $\mathrm{M}$, Rodríguez-Celis CA, Quiñones T, Sánchez-Suárez L, Patarroyo ME, Patarroyo MA. High Plasmodium malariae prevalence in an endemic area of the Colombian Amazon region. PLoS One. 2016 Jul;11:e0159968. [PubMed] [Google Scholar]

31. Vergara J, Hurtado S, Alvarez VH, Arévalo M, Herrera S. Caracterización de la transmisión de Plasmodium malariae en cuatro regiones colombianas endémicas de malaria. Biomedica. 2001;21:53-61. Spanish. [Google Scholar]

32. Cox-Singh J. Zoonotic malaria: Plasmodium knowlesi, an emerging pathogen. Curr Opin Infect Dis. 2012 Oct;25:530-6. [PubMed] [Google Scholar]

33. Millar SB, Cox-Singh J. Human infections with Plasmodium knowlesi-zoonotic malaria. Clin Microbiol Infect. 2015 Jul;21:640-8. [PubMed] [Google Scholar]

34. Duque-Isaza YY. Malaria gestacional vivax: genotipos plasmodiales y perfil inmunológico en primoinfección y recurrencia; Colombia, 2018-2019. Medellín: Universidad de Antioquia; 2020. 165 p. Spanish.

35. Rajwani J, Klinger CM, Arango E, Arroyo MI, Sabbagh A, Maestre A, Dacks JB, Gnidehou S, Yanow SK. Genetic analysis of ID1-DBL2X predicts its validity as a vaccine candidate in Colombia and supports at least two independently introduced Plasmodium falciparum populations in the region. Infect Genet Evol. 2017 Nov;55:175-85. [PubMed] [Google Scholar]

36. Dobaño $C$, Bardají $A$, Arévalo-Herrera M, MartínezEspinosa FE, Bôtto-Menezes C, Padilla N, Menegon M, Kochar S, Kochar SK, Unger H, Ome-Kaius $M$, Rosanas-Urgell A, Malheiros A, Castellanos ME, Hans D, Desai M, Casellas A, Chitnis CE, Severini C, Mueller
I, Rogerson S, Menéndez C, Requena P. Cytokine signatures of Plasmodium vivax infection during pregnancy and delivery outcomes. PLoS Negl Trop Dis. 2020 May;14:e0008155. [PubMed] [Google Scholar]

37. Gnidehou S, Doritchamou J, Arango EM, Cabrera A, Arroyo MI, Kain KC, Ndam NT, Maestre A, Yanow SK. Functional antibodies against VAR2CSA in nonpregnant populations from Colombia exposed to Plasmodium falciparum and Plasmodium vivax. Infect Immun. 2014 Jun;82:2565-73. [PubMed] [Google Scholar]

38. Lopez-Perez M, Larsen MD, Bayarri-Olmos R, Ampomah $P$, Stevenson L, Arévalo-Herrera M. IgG responses to the Plasmodium falciparum antigen VAR2CSA in Colombia are restricted to pregnancy and are not induced by exposure to Plasmodium vivax. Infect Immun. 2018 Jul;86:e00136-18. [PubMed] [Google Scholar]

39. Gnidehou S, Mitran CJ, Arango E, Banman S, Mena A, Medawar E, Lima BAS, Doritchamou J, Rajwani J, Jin A, Gavina K, Ntumngia F, Duffy P, Narum D, Ndam NT, Nielsen MA, Salanti A, Kano FS, Carvalho LH, Adams JH, Maestre A, Good MF, Yanow SK. Cross-species immune recognition between Plasmodium vivax Duffy binding protein antibodies and the Plasmodium falciparum surface antigen VAR2CSA. J Infect Dis. 2019 Jan;219:110-20. [PubMed] [Google Scholar]

40. Gnidehou S, Yanow SK. VAR2CSA antibodies in non-pregnant populations. Trends Parasitol. 2021 Jan;37(1):65-76. [PubMed] [Google Scholar]

41. Mitran CJ, Mena A, Gnidehou S, Banman S, Arango E, Lima BAS, Lugo H, Ganesan A, Salanti A, Mbonye A, Ntumngia F, Barakat K, Adams J, Kano F, Carvalho L, Maestre A, Good M, Yanow. Antibodies to cryptic epitopes in distant homologues underpin a mechanism of heterologous immunity between Plasmodium vivax PvDBP and Plasmodium falciparum VAR2CSA. mBio. 2019 Oct;10:e02343-19. [PubMed] [Google Scholar]

42. Fowkes FJ, McGready R, Cross NJ, Hommel M, Simpson JA, Elliott SR, Richards JS, Lackovic K, Viladpai-Nguen J, Narum D, Tsuboi T, Anders RF, Nosten F, Beeson JG. New insights into acquisition, boosting, and longevity of immunity to malaria in pregnant women. J Infect Dis. 2012 Nov;206:1612-21. [PubMed] [Google Scholar]

43. Ayadi I, Balam S, Audran R, Bikorimana JP, Nebie I, Diakité $M$, Felger I, Tanner $M$, Spertini $F$, Corradin G, Arevalo M, Herrera S, Agnolon V. P. falciparum and $P$. vivax orthologous coiled-coil candidates for a potential cross-protective vaccine. Front Immunol. 2020 Oct;11:574330. [PubMed] [Google Scholar]

44. Gonzalez L, Vega J, Ramirez JL, Bedoya G, CarmonaFonseca J, Maestre A. Relationship between Duffy blood groups genotypes and malaria infection in different ethnic groups of Choco- Colombia. Colombia Médica. 2012 Sep;43:189-95. [PubMed] [Google Scholar] 
45. Marchesini PCJ. Reducing the burden of malaria in pregnancy. Geneva: World Health Organization; 2004. $2 \mathrm{p}$.

46. Rijken MJ, McGready R, Boel ME, Rogerson S, Nosten F. Malaria in pregnancy in the Asia-Pacific region. Lancet Infect Dis. 2012 Jan;12:75-88. [PubMed] [Google Scholar]

47. Carmona-Fonseca J, Arango EM. Asymptomatic plasmodial infection in pregnant women: a global scenario. J Vector Borne Dis. 2017 Jul-Sep;54:201-6. [PubMed] [Google Scholar]

48. Carmona-Fonseca J, Maestre A. Incidencia de las malarias gestacional, congénita y placentaria en Urabá (antioquia, colombia), 2005-2007. Revista Colombiana de Obstetricia y Ginecología. 2009;60:19-33. Spanish.

49. Maestre A, Carmona-Fonseca J. Immune responses during gestational malaria: a review of the current knowledge and future trend of research. J Infect Dev Ctries. 2014 Apr;8:391-402. [PubMed] [Google Scholar]

50. Castro-Cavadía C, Carmona-Fonseca J. Assessment of the efficacy and safety of chloroquine monotherapy for the treatment of acute uncomplicated gestational malaria caused by P. vivax, Córdoba, Colombia, 20152017. Rev Colomb Obstet Ginecol. 2020 Mar;71:21-33. [PubMed] [Google Scholar]

51. Carmona-Fonseca J, Agudelo-García OM, ArangoFlórez E. Eficacia terapéutica y eventos adversos de tratamientos para malaria vivax y malaria falciparum en gestantes en las regiones de Urabá y Alto San Jorge, Colombia, 2008-2011. Rev Colomb Obstet Ginecol. 2013;64:27-37. Spanish. [Google Scholar]

52. Arroyo Arroyo MI. Eficacia de varios esquemas de dosificación de primaquina contra la gametocitemia de Plasmodium falciparum. Medellín: Universidad de Antioquia; 2015. 120 p. Spanish. 